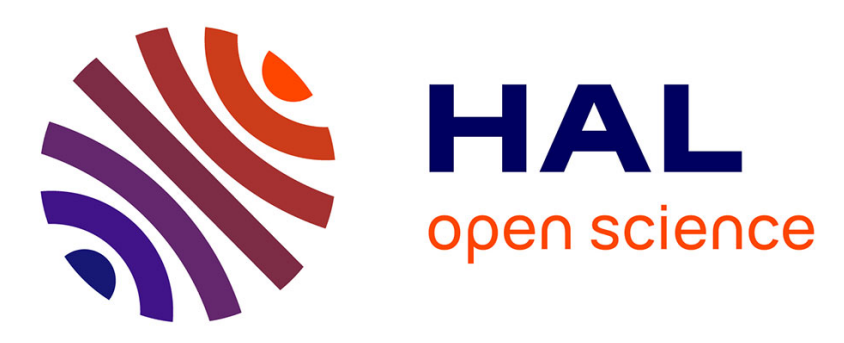

\title{
Influence of colemanite on the fire retardancy of ethylene-vinyl acetate and ethylene-methyl acrylate copolymers
}

Florian Cavodeau, Amandine Viretto, Belkacem Otazaghine, José-Marie Lopez-Cuesta, Christelle Delaite

\section{To cite this version:}

Florian Cavodeau, Amandine Viretto, Belkacem Otazaghine, José-Marie Lopez-Cuesta, Christelle Delaite. Influence of colemanite on the fire retardancy of ethylene-vinyl acetate and ethylene-methyl acrylate copolymers. Polymer Degradation and Stability, 2017, 144, pp.401-410. 10.1016/j.polymdegradstab.2017.08.016 . hal-02892704

\section{HAL Id: hal-02892704 https://hal.science/hal-02892704}

Submitted on 26 May 2021

HAL is a multi-disciplinary open access archive for the deposit and dissemination of scientific research documents, whether they are published or not. The documents may come from teaching and research institutions in France or abroad, or from public or private research centers.
L'archive ouverte pluridisciplinaire HAL, est destinée au dépôt et à la diffusion de documents scientifiques de niveau recherche, publiés ou non, émanant des établissements d'enseignement et de recherche français ou étrangers, des laboratoires publics ou privés. 


\title{
Influence of colemanite on the fire retardancy of ethylene-vinyl acetate and ethylene-methyl acrylate copolymers
}

\author{
Florian Cavodeau ${ }^{\mathrm{a}}$, Amandine Viretto ${ }^{\mathrm{a}}$, Belkacem Otazaghine ${ }^{\mathrm{a}, *}$, \\ José-Marie Lopez-Cuesta ${ }^{\mathrm{a}}$, Christelle Delaite ${ }^{\mathrm{b}}$ \\ a Centre des Matériaux des Mines d'Alès (C2MA), 6 Avenue de Clavières, 30319 Alès Cedex, France \\ b Laboratoire de Photochimie et d'Ingénierie Macromoléculaires (LPIM), 3 bis Rue Alfred Werner, 68100 Mulhouse, France
}

\begin{abstract}
A B S T R A C T
In the present work, colemanite, a hydrated calcium borate, was used as co-filler in aluminium hydroxide/ethylene-vinyl acetate copolymers (ATH/EVA). The presence of colemanite showed an improvement of the fire properties of composites. However, this additive does not act as a synergistic agent with ATH, but seems to increase significantly fire properties by his own. The formation of an expanded layer during cone calorimetry tests insulates the sample and reduces the heat release rate (HRR) values. The performance is ascribed to the hardening of the barrier layer due to the modification of colemanite structure at high temperature. Moreover, to study its mechanisms of fire retardancy and to investigate its potential synergistic effects, colemanite was also introduced as co-filler in magnesium hydroxide (MH)/EVA, ATH/ethylene-methyl acrylate (EMA) and MH/EMA composites.
\end{abstract}

Keywords:

Flame retardancy

Aluminum hydroxide

Magnesium hydroxide

EVA

EMA

Colemanite

\section{Introduction}

Ethylene-vinyl acetate (EVA) copolymers are commonly used in the cable industry, due to their properties and processing characteristics. However, as the polymer decomposes under heat, a flame can easily be produced, presenting fire risks. In order to achieve standards of fire reaction, a large amount of fire retardant (FR) systems has to be introduced during the process [1]. In EVA copolymers, hydrated mineral fillers, such as aluminium hydroxide (ATH) and magnesium hydroxide (MH) are widely used as flame retardant systems at very high loadings (up to $65 \mathrm{wt} \%$ ) [2-5].

Ethylene-methyl acrylate (EMA) copolymers are an alternative to EVA, recently developed for the cable industry. Mechanical properties are similar to EVA, with a major difference concerning processing characteristics, as the Melt Flow Index (MFI) is higher for EMA [6]. As for EVA, a large amount of FR systems is generally introduced in order to bring efficient fire retardancy. Hydrated fillers are also adapted, with a preference for $\mathrm{MH}$ due to its degradation temperature $[7,8]$. The structures of EVA and EMA are presented on Fig. 1.

\footnotetext{
* Corresponding author.

E-mail address: belkacem.otazaghine@mines-ales.fr (B. Otazaghine).
}

To enhance fire properties of a filled EVA or EMA, other components such as borates [9,10], organoclays [11,12] and silica [13,14] can be used in association with hydroxides. These compounds improve the flame retardant properties of the polymer by providing additional reactions and can entail the formation of an expanded structure, the creation of a vitreous layer or the modification of the degradation pathway of the polymer. Borates, such as zinc borate, borax or boric acid have been studied to improve the fire properties of various polymers [15]. Borates and clays were also used in combination with intumescent system components such as ammonium polyphosphate and pentaerythritol (APP and PER), to increase the fire-proofing of different polymers (PP, PE, EVA ...) [16,17].

Due to the cost or to the limit of efficiency of certain systems, alternatives have to be found for the fire retardancy of materials requiring high levels of fire performance, such as the building industry.

This study presents the potential interest of colemanite as a fire retardant in EVA and EMA copolymers. Colemanite is a natural hydrated calcium borate able to release structural water according to an endothermic degradation. Its interest as a flame retardant was already investigated, particularly in ethylene-propylene copolymers (in combination with halogen-antimony systems) [18] and high impact polystyrene [19]. First, characterization of the 


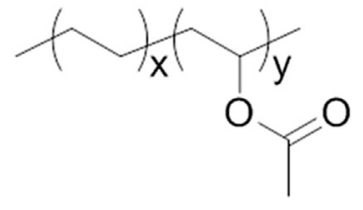

\section{EVA}

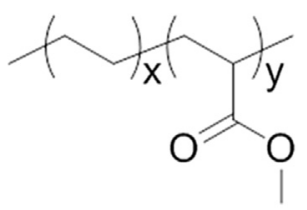

EMA
Fig. 1. General structures of the ethylene-vinyl acetate (EVA) and ethylene-methyl acrylate (EMA) copolymers.

filler was carried out and then, colemanite was introduced at different percentages in EVA/ATH, EVA/MH, EMA/ATH and EMA/ $\mathrm{MH}$ composites, to replace a fraction of the initial hydrated fillers. The thermal degradation and fire behavior were then investigated using TGA analysis, cone calorimeter and epiradiator. By studying cone calorimeter curves, structures of residues and mineral structure modifications of colemanite with temperature, it is expected to propose a mechanism of action of the filler as a fire retardant regarding the possible reduction of heat release rate and formation of an efficient barrier layer. Analysis of smoke release and selfextinguishment properties are also carried out to investigate the interest of colemanite as a fire retardant, used alone or in combination with hydroxides.

\section{Experimental}

\subsection{Materials}

EVA used was a thermoplastic-elastomeric grade Alcudia ${ }^{\circledR}$ PA440 (Repsol), with a melt flow index of $7 \mathrm{~g} / 10 \mathrm{~min}\left(190{ }^{\circ} \mathrm{C}\right.$, $2.16 \mathrm{~kg}$ ) and a vinyl acetate content of $28 \mathrm{wt} \%$. EMA used was a thermoplastic-elastomeric grade Lotryl ${ }^{\circledR} 24$ MA 005 (Arkema), with a melt flow index of $0.5 \mathrm{~g} / 10 \mathrm{~min}\left(190{ }^{\circ} \mathrm{C}, 2.16 \mathrm{~kg}\right)$ and a methyl acrylate content of $24 \mathrm{wt} \%$. The major characteristics of the two polymers are presented in Table 1.

Aluminium hydroxide (ATH) was supplied by Alteo under the name $\mathrm{SH} 15$, with a median diameter $\left(\mathrm{d}_{50}\right)$ of $1.5 \mu \mathrm{m}$ and obtained by grinding using a water steam process. Magnesium hydroxide $(\mathrm{MH})$ is a Magnifin ${ }^{\circledR} \mathrm{H} 10$ grade supplied by Martinswerk, with a $\mathrm{d}_{50}$ between 0.80 and $1.10 \mu \mathrm{m}$.

Colemanite used is a mineral rock extracted from a quarry located in Turkey, supplied by the French company Emaux Soyer and used as a raw material for the ceramic and glass industry [20]. Colemanite is composed of hydrated calcium borate with a chemical structure of $2 \mathrm{CaO} ; 3 \mathrm{~B}_{2} \mathrm{O}_{3} ; 5 \mathrm{H}_{2} \mathrm{O}$ [21]. Colemanite was ground by Emaux Soyer to obtain a powder, with a $\mathrm{d}_{50}$ of about $10 \mu \mathrm{m}$. As the colemanite used is a natural mineral, its content of water may vary in the sample. Thermogravimetric (TGA) measurements present water content between 22 and $26 \mathrm{wt} \%$ at $400{ }^{\circ} \mathrm{C}$ (average mass loss of $24.2 \mathrm{wt} \%$ ) and an exothermic transition at $650-700{ }^{\circ} \mathrm{C}$, corresponding to the crystallization of calcium borate $\left(\mathrm{CaB}_{2} \mathrm{O}_{3}\right)$ [22]. As a comparison, ATH and $\mathrm{MH}$ respectively release $34.6 \mathrm{wt} \%$ [4] and $31 \mathrm{wt} \%$ [5] of structural water.
The characteristics of fillers are presented in Table 2. The powder true density was measured with a gas pycnometer AccuPyc 1330 (Micromeritics). Specific surface area $\left(\mathrm{S}_{\mathrm{BET}}\right)$ was measured using a BET SA 3100 (Beckman-Coulter). Particle size $\left(d_{50}\right)$ was measured with a laser diffraction particle size analyser LS 13320 (Beckman-Coulter), using an ultrasonic device to disagglomerate particles.

\subsection{Processing}

Processing was carried out by mixing the fillers with the molten EVA or EMA pellets using a twin-screw extruder (Clextral BC21, $900 \mathrm{~mm}$ ) at $160{ }^{\circ} \mathrm{C}$ and then pressed using an injection moulding machine (Krauss-Maffei 50T-KM50/180CX). Sheets of $100 \times 100 \times 4$ $\mathrm{mm}^{3}$ were prepared at $140{ }^{\circ} \mathrm{C}$ under a pressure of 100 bars for $5 \mathrm{~min}$. All formulations are presented in Table 3.

\subsection{Experimental techniques}

Thermogravimetric analysis (TGA) was carried out using a Pyris 1 TGA (PerkinElmer) at heating rate $10^{\circ} \mathrm{C} / \mathrm{min}$ under synthetic air. Differential thermal analysis (DTA) was done using a STA 409 device (Netzch). The range of temperature measurements was $20-800{ }^{\circ} \mathrm{C}$.

Flammability was studied using a cone calorimeter (Fire Testing Technology - FTT) according to the standard ISO 5660 (sample dimensions $100 \times 100 \times 4 \mathrm{~mm}^{3}$ ). External heat flux was set to $50 \mathrm{~kW} /$ $\mathrm{m}^{2}$. The variations of Heat Release Rate (HRR), peak of Heat Release Rate (pHRR), time of pHRR and Total Heat Release (THR) were measured. The appearance of a second peak, after pHRR, was also studied to estimate the barrier effect. Measurements were carried out on three samples for each formulation. The cone calorimeter results are similar in a same series. In order to estimate the theoretical maximum THR, the formulations were analyzed by Pyrolysis Combustion Flow Calorimetry (PCFC) [23]. An anaerobic pyrolysis was performed with a FTT apparatus, with a heating rate of $1{ }^{\circ} \mathrm{C} / \mathrm{s}$. The maximum pyrolysis temperature was $750{ }^{\circ} \mathrm{C}$ and the combustion temperature was $900{ }^{\circ} \mathrm{C}$, corresponding to a complete combustion.

The self-extinguishing properties of the formulations were studied, using an epiradiator device (NF P 92-505 standard). Samples of $70 \times 70 \times 4 \mathrm{~mm}^{3}$ were exposed to a $500 \mathrm{~W}$ epiradiator, with an irradiance of $37 \mathrm{~kW} / \mathrm{m}^{2}$. The principle of this method is to heat a sample until the ignition, and then to remove the epiradiator. When the flame out occurs, the epiradiator is replaced above the sample until the next ignition. The test lasts $5 \mathrm{~min}$, and the measured values are the Time To Ignition (TTI), the number of ignitions and their duration.

Dynamic rheological measurements were carried out to assess the change in complex viscosity using an ARES rheometer (Rheometric Scientific). The melt viscoelasticity tests in oscillatory shear mode were performed with parallel plate equipment at a fixed temperature of $160{ }^{\circ} \mathrm{C}$ using $0.5 \%$ strain and a frequency ranging from $10^{-1} \mathrm{~s}^{-1}$ to $10^{2} \mathrm{~s}^{-1}$. The testing temperature was chosen relatively low to avoid eventual unwanted variations related to the

Table 1

Characteristics of EVA and EMA from supplier data.

\begin{tabular}{|c|c|c|c|c|c|c|c|}
\hline & $\begin{array}{l}\text { Vinyl acetate or Methyl acrylate } \\
\text { content (\% wt) }\end{array}$ & $\begin{array}{l}\text { Melt Flow Index }\left(190^{\circ} \mathrm{C} /\right. \\
2.16 \mathrm{~kg})(\mathrm{g} / 10 \mathrm{~min})\end{array}$ & $\begin{array}{l}\text { Density at } 23{ }^{\circ} \mathrm{C} \\
\left(\mathrm{g} / \mathrm{cm}^{3}\right)\end{array}$ & $\begin{array}{l}\text { Melting } \\
\text { Point }\left({ }^{\circ} \mathrm{C}\right)\end{array}$ & $\begin{array}{l}\text { Elongation at } \\
\text { break }(\%)\end{array}$ & $\begin{array}{l}\text { Tensile strength at } \\
\text { break (MPa) }\end{array}$ & $\begin{array}{l}\text { Shore } \\
\text { Hardness A }\end{array}$ \\
\hline $\begin{array}{l}\text { EVA: Alcudia }{ }^{\circledR} \\
\quad \text { PA-440 }\end{array}$ & 28 & 7 & 0.95 & 71 & 760 & 22 & 80 \\
\hline $\begin{array}{r}\text { EMA: Lotryl }^{\circledR} \\
24 \text { MA } 005\end{array}$ & 24 & $0.4-0.6$ & 0.94 & 72 & 750 & 18 & 84 \\
\hline
\end{tabular}


Table 2

Characteristics of fillers.

\begin{tabular}{|c|c|c|c|c|c|c|}
\hline Filler & Denomination & Powder true density $\left(\mathrm{g} / \mathrm{cm}^{3}\right)$ & $\mathrm{S}_{\mathrm{BET}}\left(\mathrm{m}^{2} / \mathrm{g}\right)$ & $\mathrm{d}_{50}$ Supplier $(\mu \mathrm{m})$ & $\mathrm{d}_{50}$ Laser $(\mu \mathrm{m})$ & Mineral Composition \\
\hline ATH: SH15 & A & 2.48 & 20.58 & 1.5 & 1.7 & $\mathrm{Al}(\mathrm{OH})_{3}$ \\
\hline MH: H10 & M & 2.42 & 10.27 & 1 & 1.2 & $\mathrm{Mg}(\mathrm{OH})_{2}$ \\
\hline Colemanite & $\mathrm{C}$ & 2.42 & 23.43 & 10 & 10.9 & $2 \mathrm{CaO} ; 3 \mathrm{~B}_{2} \mathrm{O}_{3} ; 5 \mathrm{H}_{2} \mathrm{O}$ \\
\hline
\end{tabular}

thermal degradation of formulations. Indeed, ATH starts to decompose around $180^{\circ} \mathrm{C}$ [4], $\mathrm{MH} 250-300{ }^{\circ} \mathrm{C}$ [5], EVA $300^{\circ} \mathrm{C}[1]$ and EMA $400{ }^{\circ} \mathrm{C}[7]$.

An observation of the structure of formulations and residues was made using a Leica Wild M optical 10 microscope, associated to a Leica DFC 420 camera, with a $\times 10$ magnification. A SEM Quanta FEG 200 was also used to observe the samples at higher magnification. A heating plate was used to study the structural modification of the colemanite during the increase of temperatures, up to $1000^{\circ} \mathrm{C}$.

XRD analyses were carried out to study the mineral structures of the samples, and also to determine the presence of amorphous phases. An AXS D8 Advance (Bruker) was used for all the analyses. A furnace can be placed around the sample-holder, in order to study the evolution of the structure of the mineral with the temperature.

\section{Results \& discussion}

\subsection{Behavior of the colemanite with the temperature}

Fig. 2 presents TGA and DTA thermograms, in the $20-800{ }^{\circ} \mathrm{C}$ range at $10{ }^{\circ} \mathrm{C} / \mathrm{min}$ under synthetic air. TG measurement of the colemanite shows two steps of degradation. The first at $400{ }^{\circ} \mathrm{C}$, corresponding to the release of water, and the second at $650-700{ }^{\circ} \mathrm{C}$, corresponding to the crystallization of calcium borate [22]. The DTA curve confirms the endothermic degradation related to the release of water, and a supposed slight exothermic reaction related to the crystallization at high temperature.

Fig. 3 presents SEM images corresponding to the evolution of colemanite structure as function of temperature, at 20 and $700{ }^{\circ} \mathrm{C}$. At $20{ }^{\circ} \mathrm{C}$, colemanite sample is constituted of particles of heterogeneous sizes and shapes. Larges plates of about $20 \mu \mathrm{m}$ are dispersed with more pseudo-spherical elements of about $2 \mu \mathrm{m}$. This dispersion in geometrical parameters is a direct consequence of the grinding process. At $700{ }^{\circ} \mathrm{C}$, colemanite particles seem to have formed a foam-like structure by sintering. Initial particles are no longer well defines and a different mineral structure seems to have been formed at high temperature.

XRD analysis confirms the changes of the mineral structure of the colemanite at 200,600 and $800{ }^{\circ} \mathrm{C}$ (Fig. 4).

Table 3

List of formulations.

\begin{tabular}{llllll}
\hline Formulation & EVA (wt\%) & EMA (wt\%) & A (wt\%) & M (wt\%) & C (wt\%) \\
\hline 1: 40EVA/60A & 40 & - & 60 & - & - \\
2: 40EVA/50A/10C & 40 & - & 50 & - & 10 \\
3: 40EVA/30A/30C & 40 & - & 30 & - & 30 \\
4: 40EVA/60C & 40 & - & - & - & 60 \\
5: 40EVA/60M & 40 & - & - & 60 & - \\
6: 40EVA/30M/30C & 40 & - & - & 30 & 30 \\
7: 40EMA/60A & - & 40 & 60 & - & - \\
8: 40EMA/30A/30C & - & 40 & 30 & - & 30 \\
9: 40EMA/60M & - & 40 & - & 60 & - \\
10: 40EMA/50M/10C & - & 40 & - & 50 & 10 \\
11: 40EMA/30M/30C & - & 40 & - & 30 & 30 \\
12: EVA & 100 & - & - & - & - \\
13: EMA & - & 100 & - & - & - \\
\hline
\end{tabular}

The diffractogram at $200{ }^{\circ} \mathrm{C}$ corresponds to the raw colemanite [20]. The raise of temperature until $600^{\circ} \mathrm{C}$, after the release of the water of structure, leads to the formation of amorphous compounds (presence of bumps) associated with various calcium borate-based species such as inyoite $\left(\mathrm{Ca}_{2} \mathrm{~B}_{6} \mathrm{O}_{6}(\mathrm{OH})_{10}, 8 \mathrm{H}_{2} \mathrm{O}\right)$ and parasibirskite $\left(\mathrm{Ca}_{2} \mathrm{~B}_{2} \mathrm{O}_{5}\right)$. At this temperature of $600{ }^{\circ} \mathrm{C}$, the sample is still a powder.

The recrystallization occurs after $700{ }^{\circ} \mathrm{C}$ and forms a new mineral structure, resulting from the sintering, or ceramisation, of the sample. According to the analysis, a fraction of parasibirskite $\left(\mathrm{Ca}_{2} \mathrm{~B}_{2} \mathrm{O}_{5}\right)$ remains in the sample, with mainly crystalline calcium borate $\left(\mathrm{Ca}_{3}\left(\mathrm{BO}_{3}\right)_{2}\right)$. The formation of these different compounds is expected to occur during cone calorimeter tests to improve the fire behavior. Hence, the water release can produce a flame retardant effect. In addition, the sample ceramisation can lead to the formation of a cohesive barrier structure protecting the residue.

To predict the effects of the colemanite in EVA or EMA composites containing hydrated fillers, tests were directly carried out on the fillers, using the epiradiator device. The colemanite powder was heated to observe its behavior at macroscopic scale. Under the epiradiator (with an irradiance estimated at $37 \mathrm{~kW} / \mathrm{m}^{2}$ ), the increase of temperature of the sample leads to the expansion of the powder layer, due to the release of water during the thermal decomposition of both fillers. After $10 \mathrm{~min}$ of heating, the structure solidifies, due to the sintering of the colemanite. During the cooling, after the epiradiator device was removed, the sample keeps its cohesive structure. Fig. 5 presents different steps of this evolution of colemanite with heating under epiradiator device.

The ATH/colemanite 50/50 powder mixture was also studied. The behavior during the heating step is similar for only colemanite and for the ATH/colemanite 50/50 mixture. However, the residue of the mixture after epiradiator test presents white parts dispersed within the layer of colemanite (Fig. 6). These white elements seem to correspond to alumina particles. We assume that colemanite forms a cohesive layer independently of the ATH presence.

The XRD analysis of the 50/50 mixture leads to the same conclusion. The diffractogram presents the same stripes as

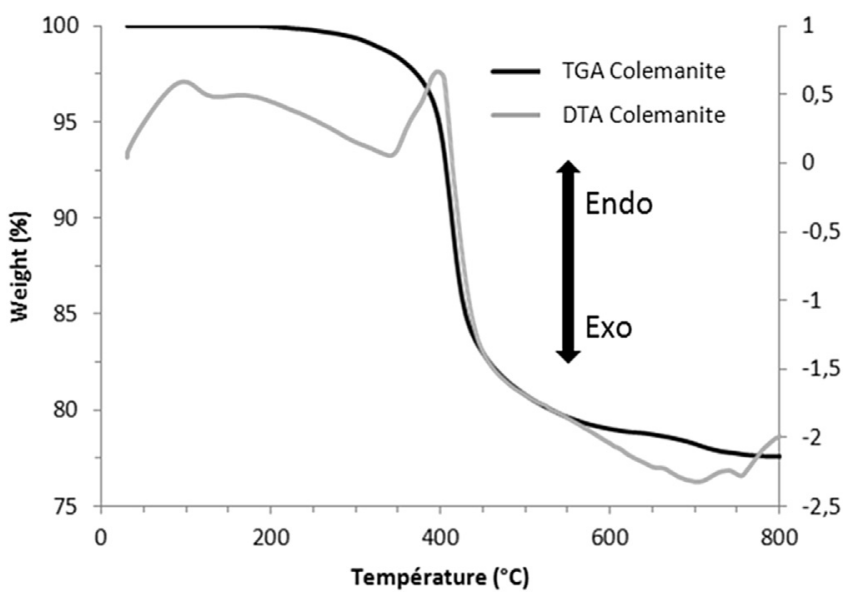

Fig. 2. TG-DT analysis of the colemanite. 

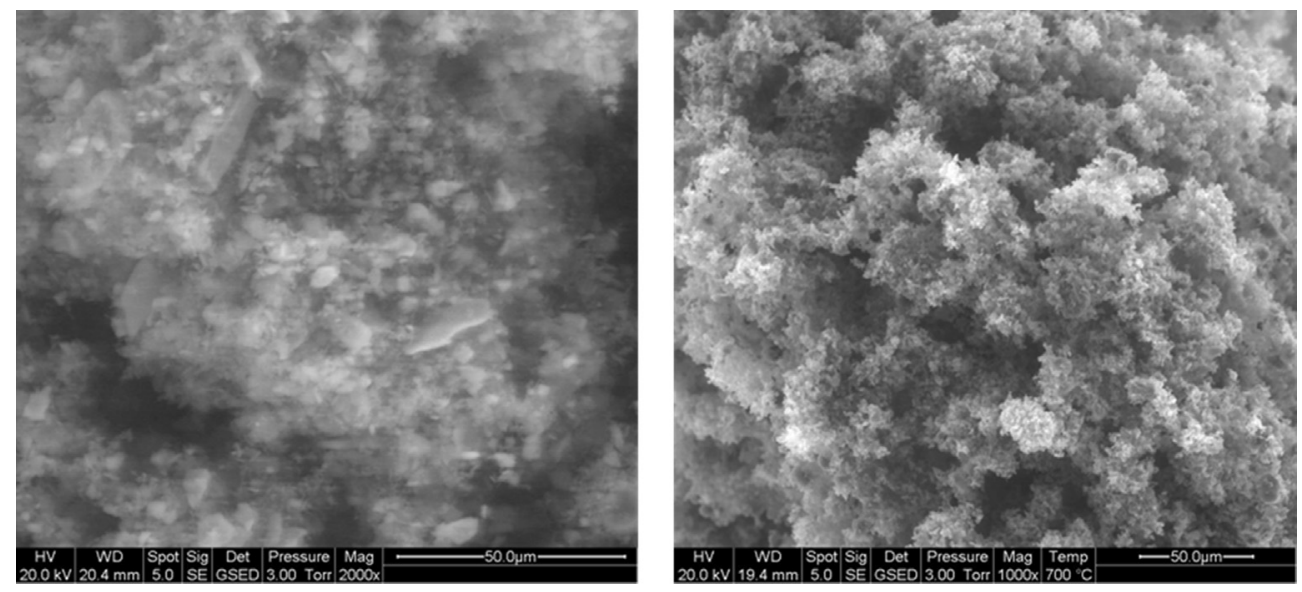

Fig. 3. SEM observations of colemanite at $20^{\circ} \mathrm{C}$ (left) and $700{ }^{\circ} \mathrm{C}$ (right) $(\times 2000)$.

colemanite at $800{ }^{\circ} \mathrm{C}$ (parasibirskite and calcium borate), but also an amorphous phase, associated to the alumina. The diffractogram is presented on Fig. 7.

Moreover, SEM observations were performed using an adaptated heating plate, able to reach temperatures up to $1000^{\circ} \mathrm{C}$. SEM images of the $50 / 50 \mathrm{ATH} /$ colemanite mixture on the heating plate are presented on Fig. 8. During the heating step, cavities appear while the particles seem to disperse. At $700-750^{\circ} \mathrm{C}$, a sponge-like structure solidifies. Particles of about $2 \mu \mathrm{m}$, corresponding to the alumina, remain separated from the solidified colemanite. This observation confirms the absence of reaction between the ATH and the colemanite during the formation of the cohesive layer.

The presence of colemanite enables to create a cohesive network at high temperature $\left(700-750^{\circ} \mathrm{C}\right)$. However, the particles obtained by the ATH degradation do not seem to be included in the mineral structure formed by the crystallized calcium borate.

\subsection{Fire retardancy characterization of EVA composites}

First, EVA/ATH/colemanite composites were tested at cone calorimeter (irradiance $50 \mathrm{~kW} / \mathrm{m}^{2}$ ). Then, ATH was replaced by $\mathrm{MH}$ in order to confirm the influence of the colemanite on the fire

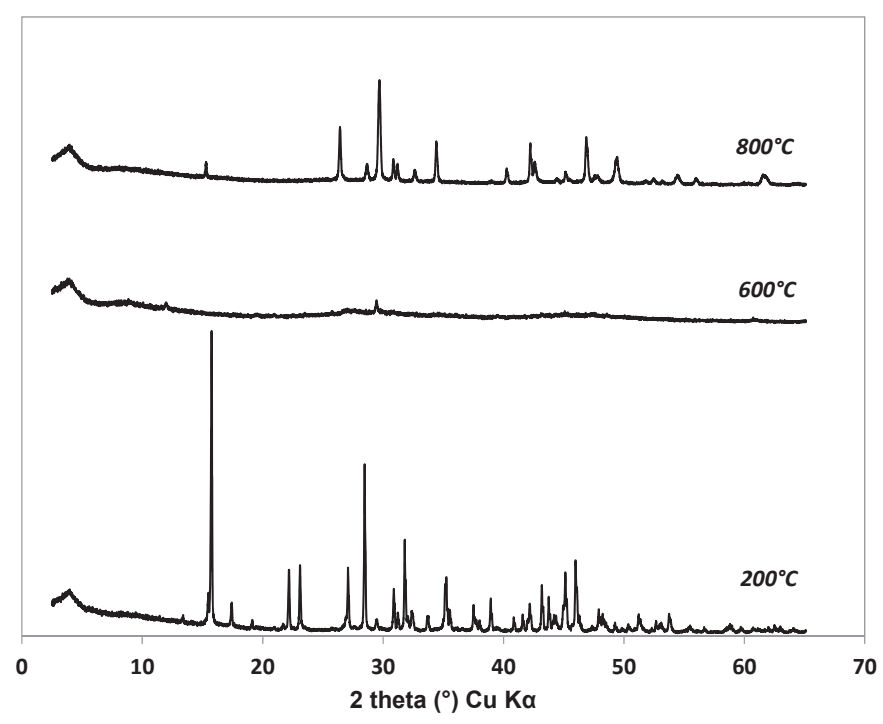

Fig. 4. XRD diffractogram of the colemanite at 200,600 and $800{ }^{\circ} \mathrm{C}$. retardancy. Results are presented on Table 4, including Time To Ignition (TTI), peak of Heat Release Rate (pHRR), corresponding time (tpHRR), Total Heat Release (THR), Total Smoke Release (TSR) and Mass Loss. HRR curves for ATH and colemanite compositions are represented on Fig. 9.

According to the cone results, no synergistic effect between ATH and colemanite appears to occur, since the increase of the amount of colemanite used alone improves more strongly the fire retardancy of the EVA composites. The pHRR decreases and the barrier effect is more efficient with the release of water (22-26 wt\%) and with the crystallization phenomenon due to the thermal degradation of colemanite. Concerning the first part of HRR curves, the substitution of ATH with colemanite reduces both TTI and tpHRR, compared to $40 \mathrm{EVA} / 60 \mathrm{~A}$ formulation. For total substitution (40EVA/60C formulation), the tpHRR is even reduced by about 50 s and its TTI is very close to the one of the EVA alone. The delay may be due to the difference of water release temperature between ATH $\left(200{ }^{\circ} \mathrm{C}\right)$ [4] and colemanite $\left(400{ }^{\circ} \mathrm{C}\right)$ [21]. Considering that EVA begins to degrade at $300{ }^{\circ} \mathrm{C}$ [1], the formation of a flammable atmosphere and the ignition are favored with colemanite, as the dilution of the gaseous phase and the endothermic effect occur at higher temperature. Once the ignition starts, the temperature of the sample strongly increases with the flame development. Then the temperature of action of the colemanite is reached, which will limit the heat release. The observation is similar in the presence of $\mathrm{MH}$, however the intensity of the pHRR is not reduced by the presence of colemanite.

The increase of the amount of colemanite also reduces the THR and the Mass Loss. The difference with the Calculated Mass Loss confirms that a fraction of polymer residue remains at the end of the test, associated with the decrease of THR.

Furthermore, the colemanite acts as a smoke suppressor. The efficiency is higher with the increase of the amount of colemanite. For the sample $40 E V A / 50 \mathrm{~A} / 10 \mathrm{C}$, the TSR is $389.2 \mathrm{~m}^{2} / \mathrm{m}^{2}$, which is significantly lower than the TSR of the sample 40EVA/60A $\left(838.3 \mathrm{~m}^{2} / \mathrm{m}^{2}\right)$. For the sample 40EVA/60C, the TSR is reduced to $154.4 \mathrm{~m}^{2} / \mathrm{m}^{2}$. The measurement of the TSR, during cone calorimeter tests, is presented on Fig. 10.

Residues of EVA/ATH/colemanite composites present a foamlike structure, with holes and cavities. In a previous study, residues of EVA/ATH/diatomite composites presented the same kind of barrier structure [24]. It was proposed that a high viscosity during the thermal degradation enables the expansion of the structure, by retaining the gases of decomposition inside the sample. This study suggests that the expansion related to high viscosity systems is 

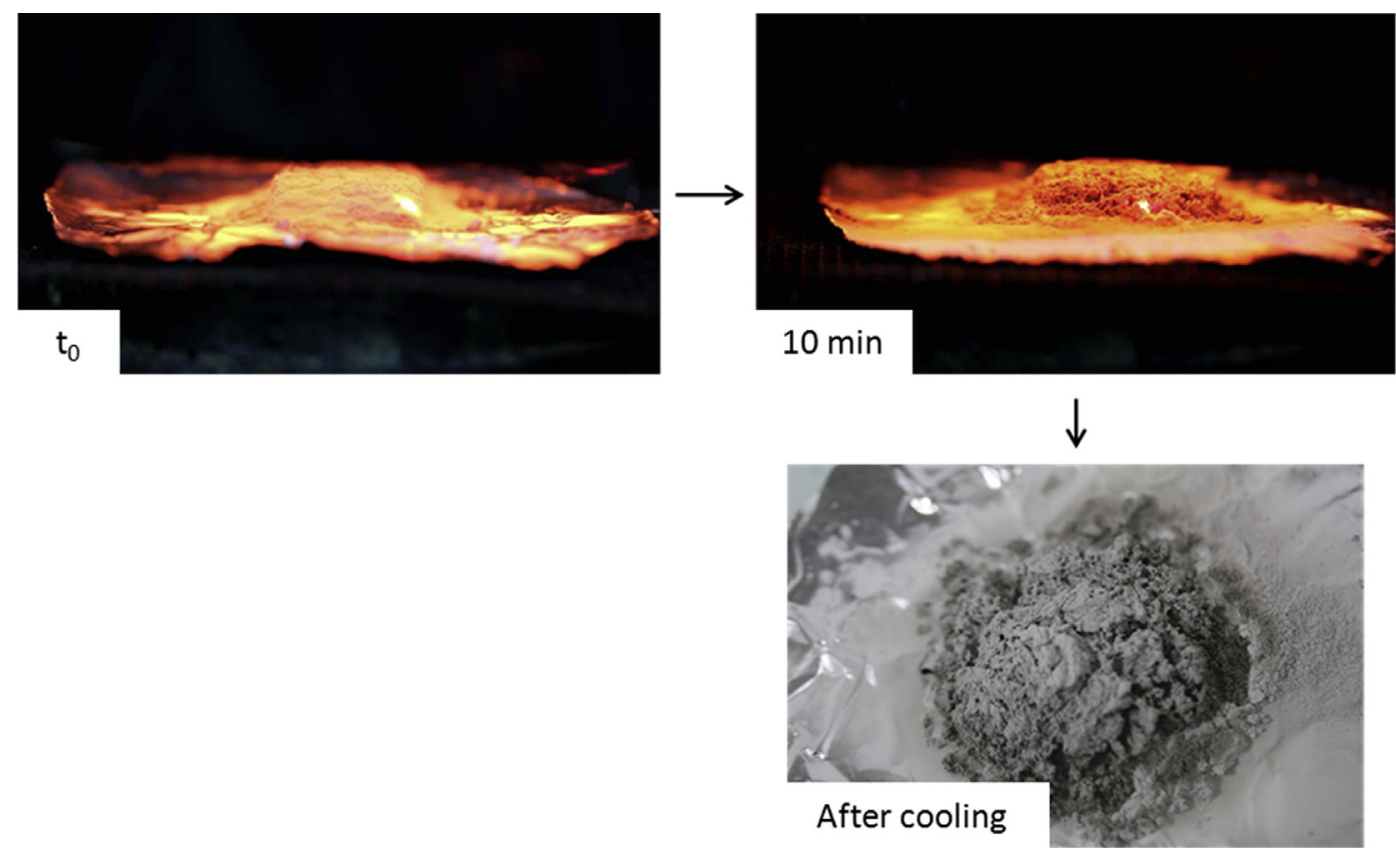

Fig. 5. Different steps of the heating experimentation on the raw colemanite under the epiradiator.

essentially due to physical mechanisms. The rheology of the EVA/ $\mathrm{ATH} /$ colemanite formulations was evaluated using a dynamic rheometer (ARES). Results are presented on Table 5.

The pHRR for the samples containing colemanite is low, such as the viscosities measured with the rheometer, compared to the ATH alone. Furthermore, the complex viscosity seems to decrease when the amount of colemanite increases. The residues of cone calorimeter present a foam-like structure, related to an efficient barrier effect (Fig. 11). Contrary to the conclusion of our previous study [24], the capacity of expansion and the pHRR reduction follow an opposite trend regarding the complex viscosity. We assume that the expansion mechanism for EVA/ATH/colemanite formulations includes chemical effects. The hardening of the sample due to the reaction of colemanite at high temperature could be the major parameter inducing the formation of a structured residue.

To estimate the fire retardant properties related to the introduction of colemanite in EVA/ATH composites, self-extinguishing tests were carried out, using epiradiator. The formulations 40EVA/ 60A, 40EVA/50A/10C and 40EVA/30A/30C were analyzed. Values measured for TTI are similar for all formulations (respectively 76, 75

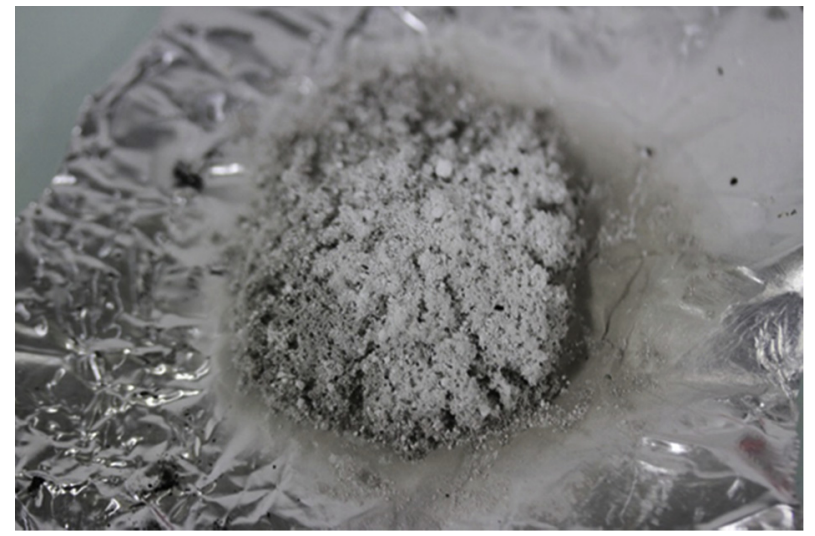

Fig. 6. Mixture of colemanite and ATH after $10 \mathrm{~min}$ of exposition under the epiradiator. and $77 \mathrm{~s}$ ). Fig. 12 presents the duration of the flaming periods for the successive ignitions occurring during the 5 min period.

During the 5 min of the test, the formulation 40EVA/60A ignites 9 times, the formulation 40EVA/50A/10C ignites 18 times and the formulation 40EVA/30A/30C ignites 19 times. After the fourth ignition, the flaming periods increase strongly for the sample 40EVA/60A. The last combustion period lasted more than $100 \mathrm{~s}$.

The self-extinguishing behavior of the ATH is limited at a certain step of the procedure. Conversely, the formulations containing the colemanite present a similar behavior. Despite flaming periods increase during the test, they remain always lower than $14 \mathrm{~s}$. Consequently, colemanite imparts a significant self-extinguishing behavior to EVA, at only 10 or $30 \mathrm{wt} \%$ of fillers.

The presence of MH in the EVA does not lead to a barrier effect and to the formation of a cohesive layer. The HRR curve of the

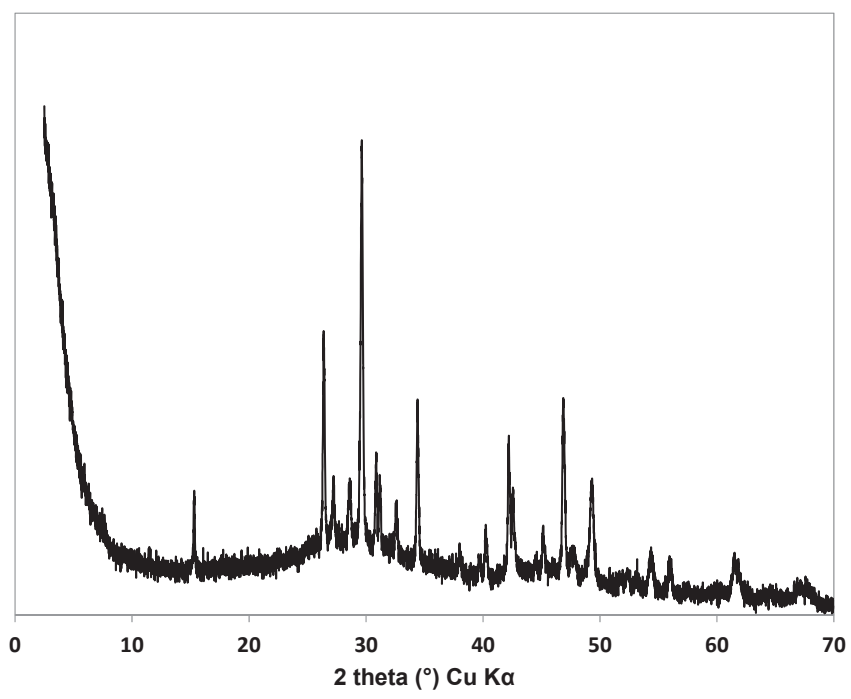

Fig. 7. XRD diffractogram of the residue of the colemanite/ATH mixture after the epiradiator test. 

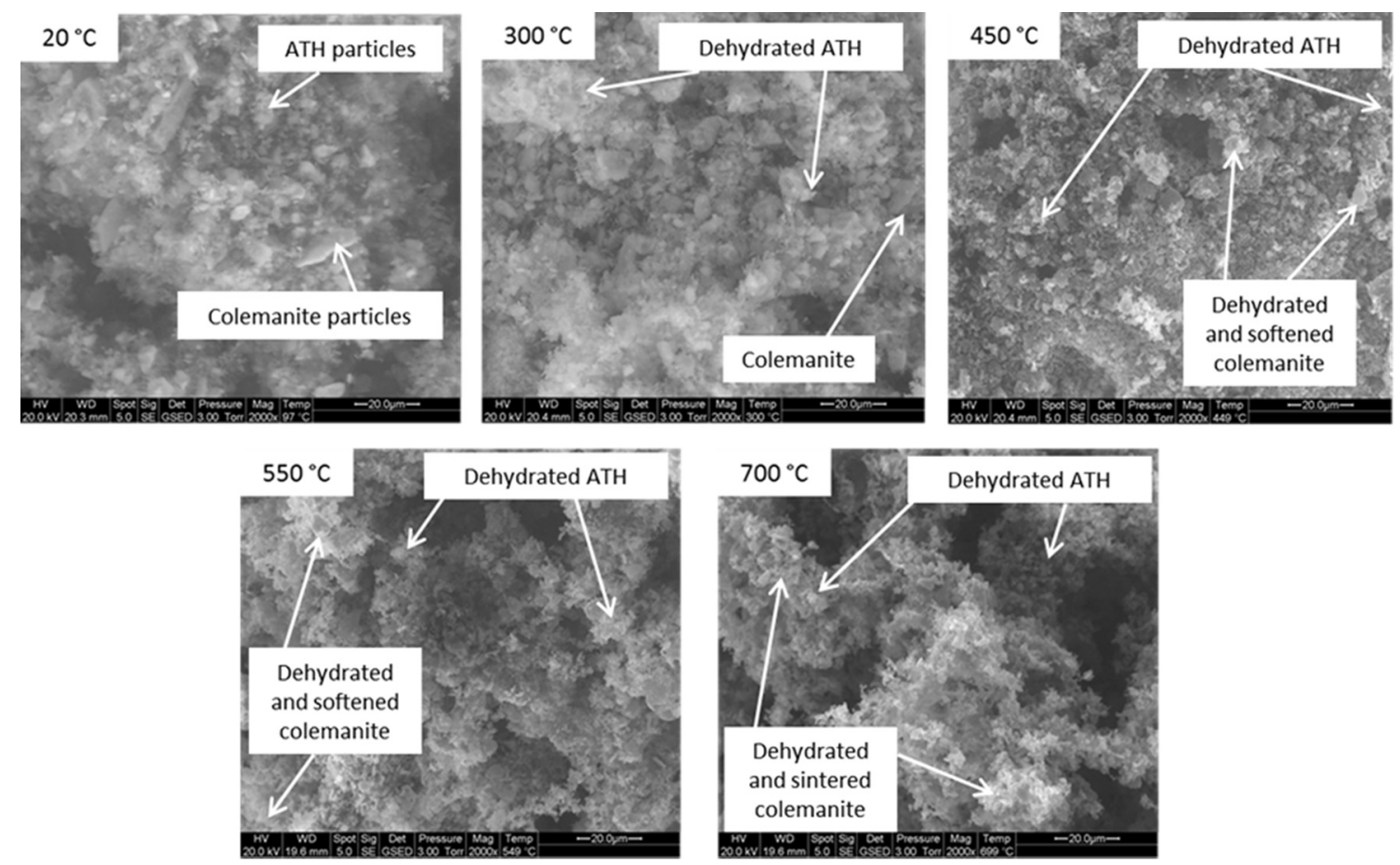

Fig. 8. SEM images of a 50/50 ATH/colemanite mixture at different temperatures.

Table 4

Results of cone calorimeter tests (EVA formulations).

\begin{tabular}{|c|c|c|c|c|c|c|c|c|}
\hline Formulation & TTI (s) & $\mathrm{pHRR}\left(\mathrm{kW} / \mathrm{m}^{2}\right)$ & tpHRR (s) & THR (kJ/g) & THR theo* $(\mathrm{kJ} / \mathrm{g})$ & Mass Loss (\%) & Calculated Mass Loss** (\%) & $\operatorname{TSR}\left(\mathrm{m}^{2} / \mathrm{m}^{2}\right)$ \\
\hline 40EVA/60A & 53 & 221.4 & 110 & 15.0 & 19.9 & 59.6 & 61.1 & 838.3 \\
\hline 40EVA/50A/10C & 60 & 188.3 & 90 & 15.1 & 21.2 & 57.8 & 59.7 & 389.2 \\
\hline 40EVA/30A/30C & 42 & 163.8 & 80 & 12.4 & 19.0 & 52.7 & 57.6 & 267.3 \\
\hline 40EVA/60C & 40 & 141.6 & 65 & 9.7 & 19.5 & 37.1 & 54.4 & 154.4 \\
\hline 40EVA/60M & 77 & 289.5 & 215 & 14.6 & 21.0 & 57.1 & 58.5 & 709.9 \\
\hline 40EVA/30M/30C & 41 & 308.4 & 100 & 16.7 & 19.2 & 54.8 & 56.5 & 652.8 \\
\hline EVA & 37 & 810.2 & 230 & 33.9 & 34.0 & 100 & 100 & 2426.5 \\
\hline
\end{tabular}

*Values obtained using PCFC analysis.

**Values calculated using TGA analysis.

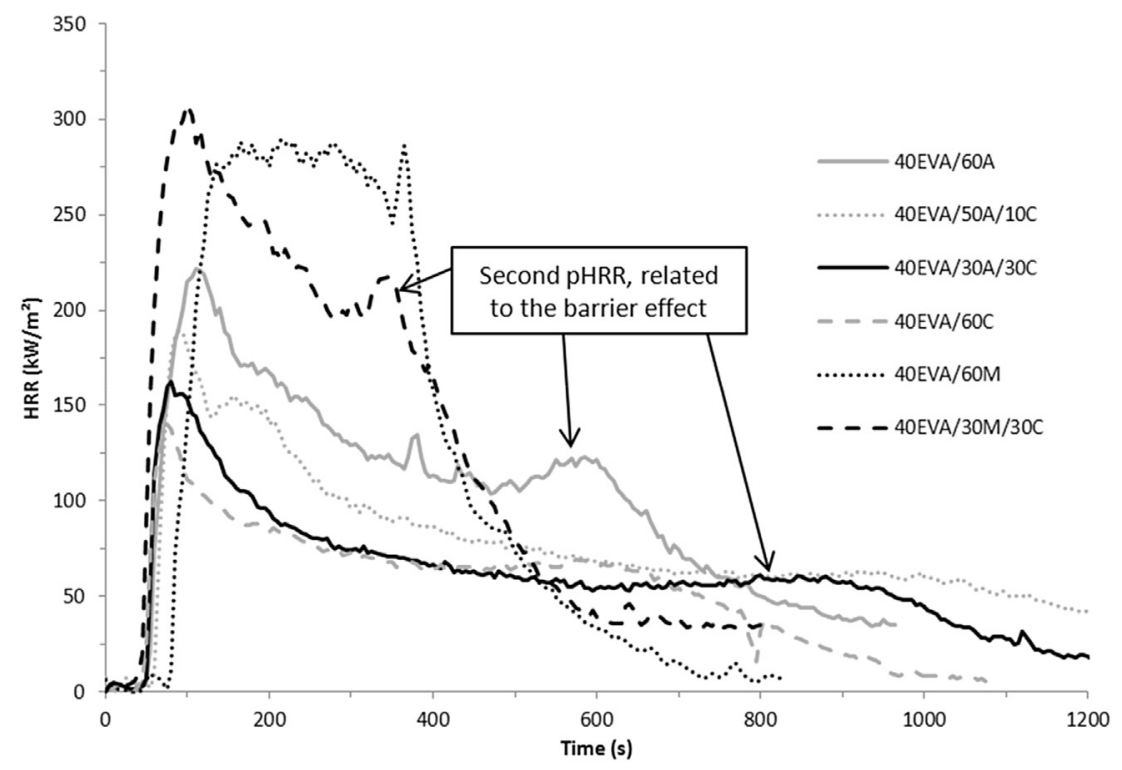

Fig. 9. HRR curves of EVA-based formulations. 


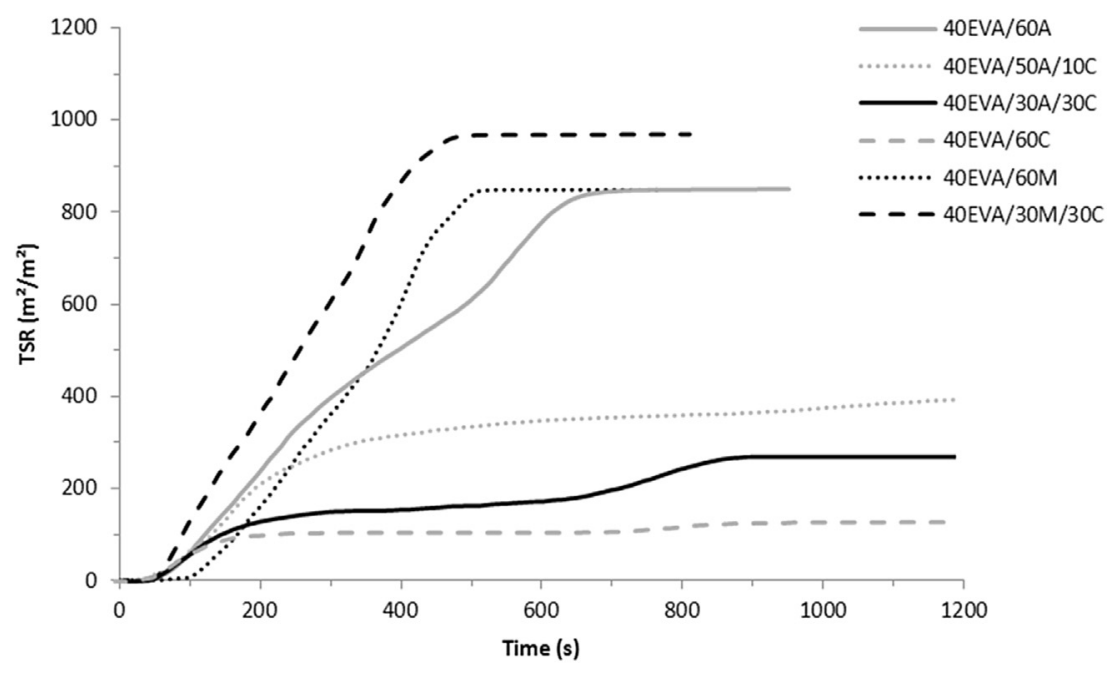

Fig. 10. TSR curves of EVA-based formulations.

Table 5

Complex viscosity measurement $\left(\eta^{*} 0\right)$ of EVA/ATH/colemanite formulations.

\begin{tabular}{lll}
\hline Formulation & $\eta^{*} 0(\mathrm{~Pa} / \mathrm{s})$ & pHRR $\left(\mathrm{kW} / \mathrm{m}^{2}\right)$ \\
\hline EVA & 7970 & 810.2 \\
40EVA/60A & 66090 & 221.4 \\
40EVA/50A/10C & 44710 & 188.3 \\
40EVA/30A/30C & 41310 & 163.8 \\
40EVA/60C & 35310 & 141.6 \\
\hline
\end{tabular}

sample 40EVA/60M and the residue of combustion confirm this aspect (Fig. 9). The pHRR of the sample 40EVA/60M is higher than the pHRR of the sample 40EVA/60A. Furthermore, the flameout of the sample containing $\mathrm{MH}$ occurs earlier and its ignition occurs later, confirming a shorter combustion period. Compared to the residues obtained with samples containing $A T H$, the residue of the sample 40EVA/60M seems to be composed of non-cohesive ashes. It does not form a cohesive and protective layer (Fig. 11).

The addition of colemanite in the sample $40 \mathrm{EVA} / 30 \mathrm{M} / 30 \mathrm{C}$ impart also fire retardancy through an efficient barrier effect, due to the sintering of the fillers, leading to a cohesive aspect of the ashes
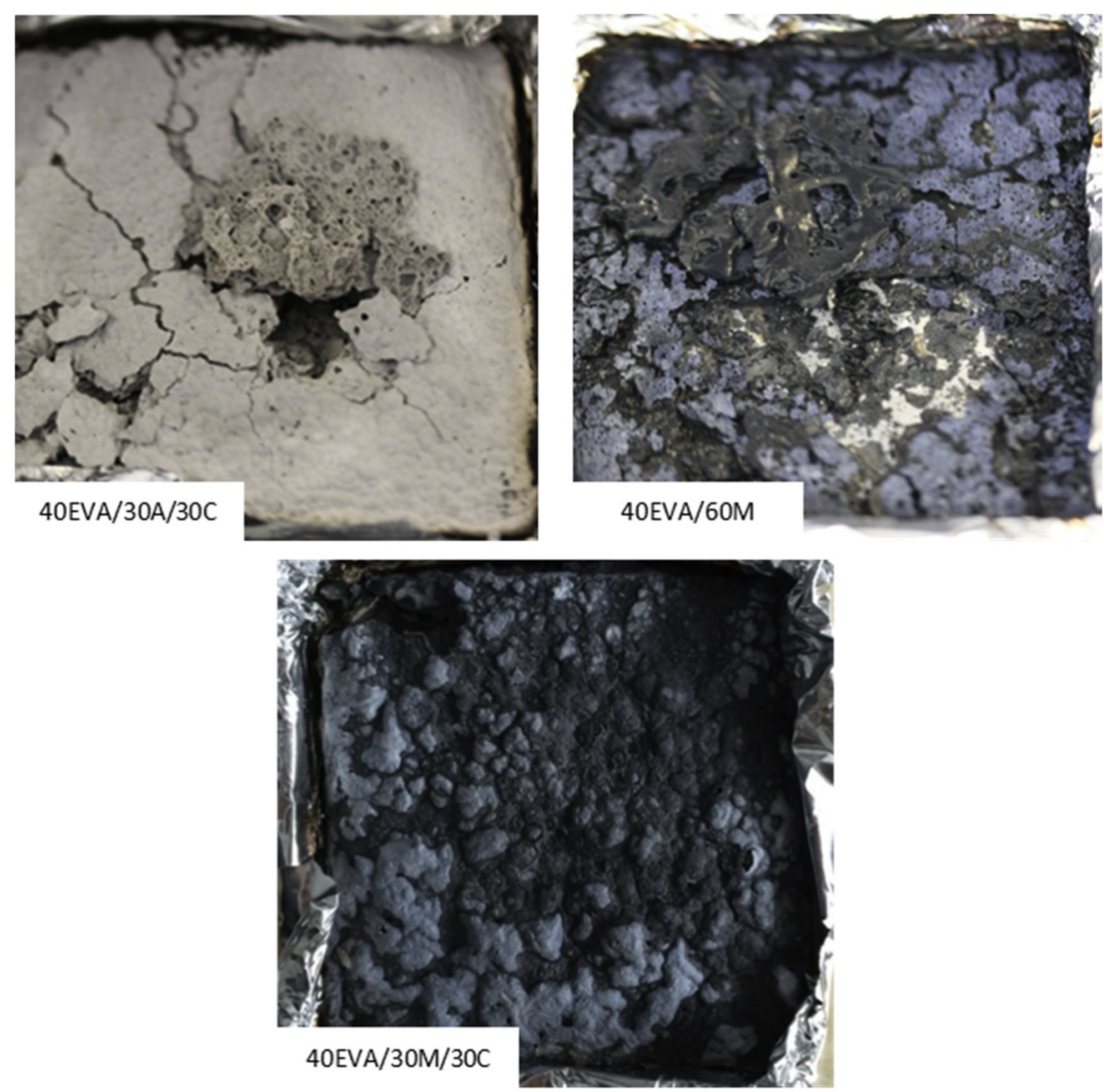

Fig. 11. Residues of EVA based samples after cone calorimeter tests. 


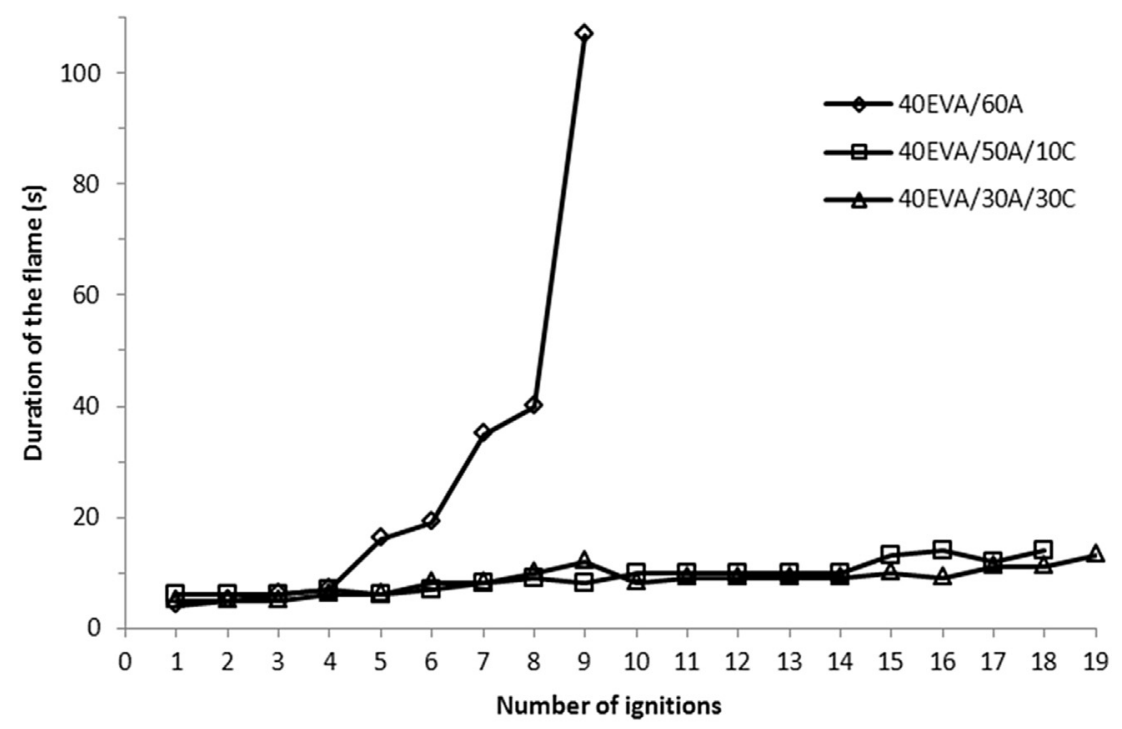

Fig. 12. Results of epiradiator tests (NF P 92-505) on EVA compositions.

formed during the combustion of the EVA/MH formulation. With colemanite, the ignition of the sample occurs earlier. Cone calorimeter curves are presented on Fig. 9.

This barrier effect is traduced on cone calorimeter curves by the presence of well-defined peaks. The pHRR is followed by a progressive decrease of the heat release and the appearance of a second pHRR. This curve shape is characteristic of a barrier effect [25]. The fire retardancy is however less efficient than for the formulations containing ATH. In presence of $\mathrm{MH}$, we can observe that the pHRR is similar with or without colemanite.

Futhermore, colemanite associated with $\mathrm{MH}$ does no longer act as an efficient smoke suppressor, compared to EVA/ATH composite (Fig. 10).

The residue of the sample $40 \mathrm{EVA} / 30 \mathrm{M} / 30 \mathrm{C}$ presents a thin cohesive layer (Fig. 11). The colemanite acts as cement for the residues, due to the sintering at high temperature.

\subsection{Fire retardancy characterization of EMA composites}

EMA/ATH-based formulations were first prepared, with the same mode of preparation than the EVA-based composites. Cone calorimeter samples of $100 \times 100 \times 4 \mathrm{~mm}^{3}$ were realized. The irradiance of the cone calorimeter was $50 \mathrm{~kW} / \mathrm{m}^{2}$. Results are presented on Table 6 and Fig. 13.

The presence of a high amount of ATH reduces the HRR value compared to pure EMA. The presence of multiple peaks for the sample 40EMA/60A confirms the formation and the cracking of a barrier layer during the fire test. The substitution of half of the ATH with colemanite reduces slightly the pHRR and the THR. However, the efficiency on the pHRR is less important for the composite with EMA matrix than the composite with EVA matrix (decrease of $\mathrm{pHRR}_{40 \mathrm{EMA} / 30 \mathrm{~A} / 30 \mathrm{C}}=15 \%$ versus decrease of $\mathrm{pHRR}_{40 \mathrm{EVA} / 30 \mathrm{~A} /}$ $30 \mathrm{c}=26 \%$, compared to the corresponding samples without colemanite). As observed with EVA formulations, the colemanite seems to act as a smoke suppressor, as the TSR decreases when colemanite is introduced in EMA/ATH and EMA/MH composites. Furthermore, TSR decreases when the amount of colemanite increase in EMA/MH formulations.

Contrary to the EVA, the filled EMA swells significantly under the cone calorimeter, as presented on Fig. 14. The increase of thickness may reach $50 \%$ in the case of the $40 \mathrm{EVA} / 30 \mathrm{~A} / 30 \mathrm{C}$ formulation. The increase of thickness is over $150 \%$ in the case of the $40 \mathrm{EMA} / 30 \mathrm{~A} / 30 \mathrm{C}$ formulation. The swelling seems to be due to the release of gases of decomposition, associated with the high Melt Flow Index of the EMA.

The swelling of the EMA is less homogeneous compared to the expansion of the structures observed for EVA formulations. The expansion is visually more punctual during the thermal decomposition of the material. In presence of colemanite, the expansion is conserved as a cohesive layer is obtained at the end of the cone calorimeter tests.

Regarding thermal degradation characteristics of the EMA, ATH is not the most adapted hydrated filler. Indeed, the ATH decomposes at $180^{\circ} \mathrm{C}$ while the degradation of EMA begins at $300^{\circ} \mathrm{C}$. $\mathrm{MH}$ degrades at $250-300{ }^{\circ} \mathrm{C}$, which corresponds more to the degradation range of EMA [7]. Results are presented on Table 6 and the cone calorimeter curves are presented in Fig. 13.

The presence of MH enhances the fire retardancy of EMA. The profile of degradation presents two distinct peaks, corresponding to a barrier effect. Contrary to the residue of the sample 40EVA/ $60 \mathrm{M}$, the residue of the sample 40EMA/60M seems to be more cohesive with no fly ashes, as presented on Fig. 14.

Addition of colemanite leads to the same observations than for EVA/ATH formulations. The sample presents an expansion when heated, and then the sintering of colemanite occurs, leading to the formation of a cohesive structure. There is no significative reduction of the pHRR in the presence of colemanite, compared to the sample 40EMA/60M. The presence of an efficient barrier effect is represented by a late and lower second pHRR around 900s, as observed on Fig. 13.

The curves of the samples $40 \mathrm{EMA} / 30 \mathrm{M} / 30 \mathrm{C}$ and $40 \mathrm{EMA} / 50 \mathrm{M} /$ $10 \mathrm{C}$ are similar. The increase of the amount of colemanite does not improve the fire properties. The substitution of $10 \%$ of $\mathrm{MH}$ with colemanite is sufficient to bring an efficient barrier effect to the EMA formulations.

Furthermore, the cone calorimeter profile of the sample 40EMA/ $50 \mathrm{M} / 10 \mathrm{C}$ is similar to the sample $40 \mathrm{EVA} / 30 \mathrm{~A} / 30 \mathrm{C}$.

\section{Conclusions}

The effect of the introduction of colemanite in EVA and EMA was investigated. Due to an endothermic release of water and to a 
Table 6

Results of cone calorimeter tests (EMA composites).

\begin{tabular}{|c|c|c|c|c|c|c|c|c|}
\hline Formulation & TTI (s) & $\mathrm{pHRR}\left(\mathrm{kW} / \mathrm{m}^{2}\right)$ & $\mathrm{t}_{\mathrm{pHRR}}(\mathrm{s})$ & THR (kJ/g) & THR theo* $(\mathrm{kJ} / \mathrm{g})$ & Mass Loss (\%) & Calculated Mass Loss** (\%) & $\operatorname{TSR}\left(\mathrm{m}^{2} / \mathrm{m}^{2}\right)$ \\
\hline 40EMA/60A & 49 & 237.2 & 90 & 17.6 & 20.2 & 56.3 & 60.8 & 705.3 \\
\hline 40EMA/30A/30C & 39 & 201.0 & 75 & 14.5 & 20.3 & 46.2 & 57.6 & 406.6 \\
\hline 40EMA/60M & 61 & 188.7 & 100 & 19.7 & 22.5 & 54.0 & 58.5 & 1640.9 \\
\hline 40EMA/50M/10C & 59 & 167.8 & 95 & 12.2 & 19.8 & 47.2 & 57.9 & 440.2 \\
\hline 40EMA/30M/30C & 47 & 166.4 & 80 & 13.0 & 19.8 & 45.1 & 56.5 & 321.0 \\
\hline EMA & 55 & 545.3 & 145 & 34.3 & 34.4 & 98.5 & 100 & 2401.4 \\
\hline
\end{tabular}

*Values obtained using PCFC analysis.

**Values calculated using TGA analysis.

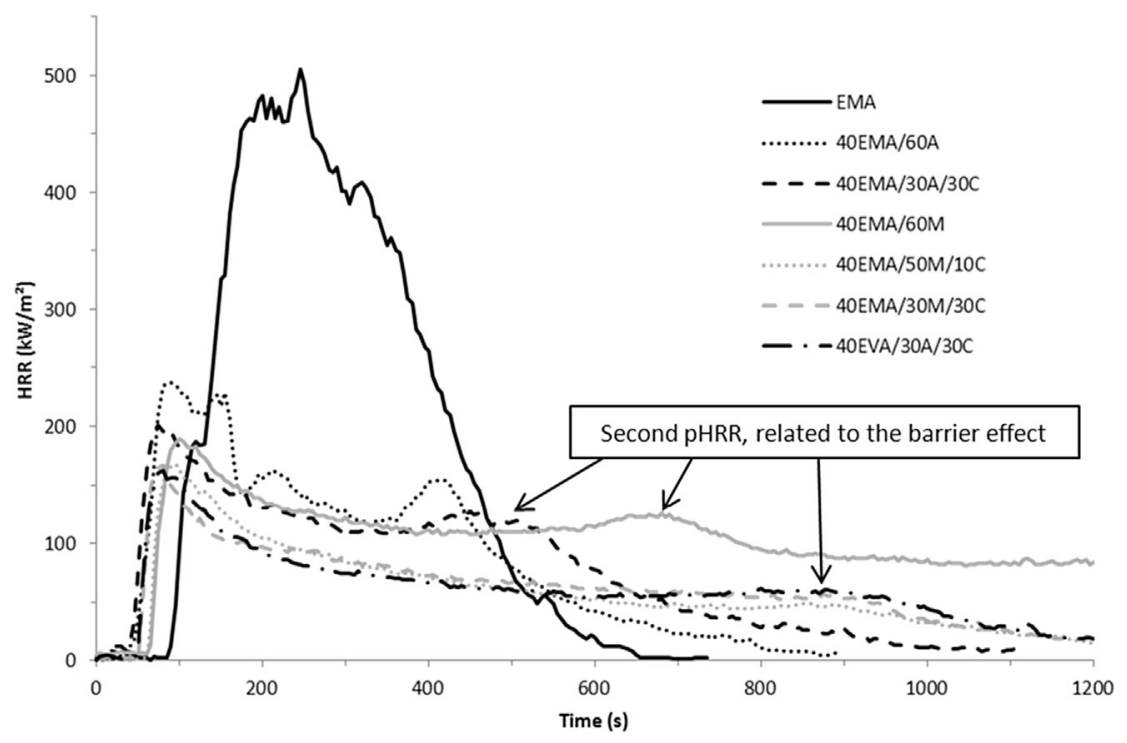

Fig. 13. HRR curves of the EMA-based formulations, compared to the sample 40EVA/30A/30C
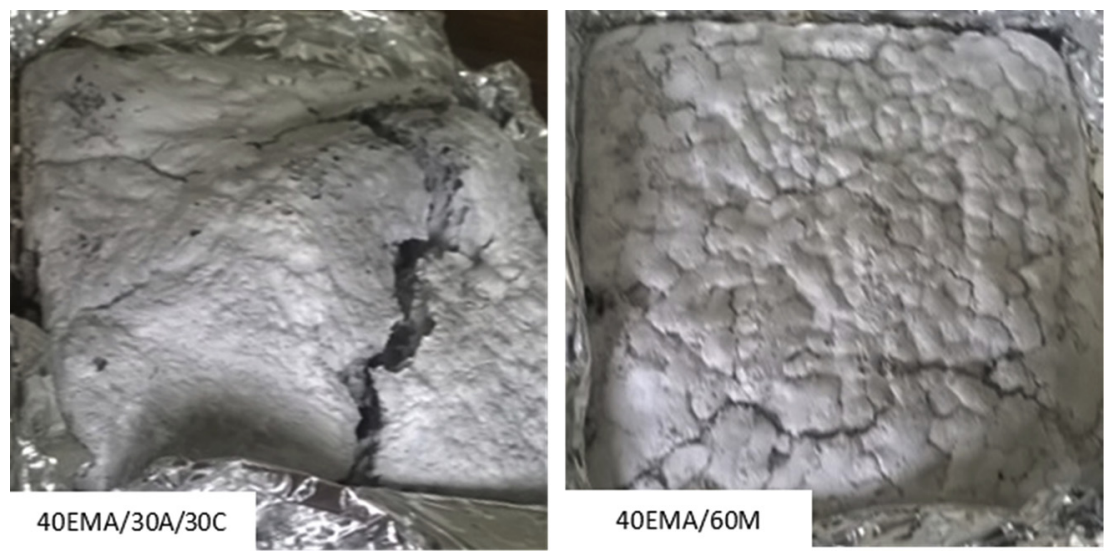

Fig. 14. Residues of EMA based samples after cone calorimeter tests.

sintering effect at the combustion temperature $\left(700-750{ }^{\circ} \mathrm{C}\right)$, colemanite shows an efficient fire retardant effect in EVA and EMA composites. The filler acts in solid phase by the formation of a cohesive barrier layer. However, no synergistic effect between the colemanite and ATH or MH is observed, since colemanite remains more efficient than its combination with the other hydrated fillers, in EVA formulations. Tests carried out on dry powders confirmed the formation of a solid structure at high temperature in presence of colemanite. Alumina obtained after the thermal degradation of the ATH remains as agglomerates, separated from the cohesive structure of crystalline calcium borate. In EVA/ATH formulations, colemanite is an efficient smoke suppressor and brings selfextinguishing properties. According to TSR measurements of cone calorimeter tests, it seems that the trend is similar with EMA/ATH and EMA/MH. The interest of the substitution of ATH with colemanite for actual use could be confirmed by normalized experiment, such as UL-94 and Limiting Oxygen Index. Indeed, conclusions obtained by this kind of experiment don't always match cone calorimeter observations.

In the case of EMA/MH formulations, addition of colemanite improves the fire retardancy by decreasing pHRR and THR values, and by the action of a barrier effect. The amount of colemanite in 
EMA/MH composites does not seem to have a major influence on the fire properties of the material; similar results are obtained with $30 \%$ and $10 \%$ of colemanite.

\section{References}

[1] A. Henderson, Ethylene-vinyl acetate (EVA) copolymers: a general review, Electr. Insul. Mag. 9 (1) (1993) 30-38.

[2] W.E. Horn, Inorganic hydroxides and hydroxycarbonates: their function and use as flame retardants, Fire Retard. Polym. Mater. (2000) 285-352.

[3] T.R. Hull, A. Witkowski, L. Hollingbery, Fire retardant action of mineral fillers, Polym. Degrad. Stab. 96 (8) (2011) 1462-1469.

[4] W. Zeng, N. Chen, Thermodynamic analysis of thermal decomposition of $\mathrm{Al}(\mathrm{OH})_{3}$, J. Mater. Sci. Technol. 13 (1997) 446.

[5] R.N. Rothon, P.R. Hornsby, Flame retardant effects of magnesium hydroxide, Polym. Degrad. Stab. 54 (1996) 383-385.

[6] K.K. Kar, J.K. Pandey, S.K. Rana, Handbook of Polymer Nanocomposites: Processing, Performance and Application, Springer, Berlin, 2014.

[7] P. Dole, J. Chauchard, Thermooxidation of poly(ethylene-co-methyl acrylate) and poly(methyl acrylate) compared to oxidative thermal aging of polyethylene, Polym. Degrad. Stab. 53 (1996) 63-72.

[8] F. Laoutid, L. Bonnaud, M. Alexandre, J.-M. Lopez-Cuesta, P. Dubois, New prospects in flame retardant polymer materials: from fundamentals to nanocomposites, Mater. Sci. Eng. 63 (3) (2009) 100-125.

[9] S. Bourbigot, M. Le Bras, R. Leeuwendal, K.K. Shen, D. Schubert, Recent advances in the use of zinc borates in flame retardancy of EVA, Polym. Degrad. Stab. 64 (1999) 419-425.

[10] C. Hoffendahl, G. Fontaine, S. Duquesne, F. Taschner, M. Mezger, S. Bourbigot, The combination of aluminum trihydroxide (ATH) and melamine borate (MB) as fire retardant additives for elastomeric ethylene vinyl acetate (EVA), Polym. Degrad. Stab. 115 (2015) 77-88.

[11] M.A. Cárdenas, D. García-López, I. Gobernado-Mitre, J.C. Merino, J.M. Pastor, J.D.D. Martínez, J. Barbeta, D. Calveras, Mechanical and fire retardant properties of EVA/clay/ATH nanocomposites - effect of particle size and surface treatment of ATH filler, Polym. Degrad. Stab. 93 (11) (2008) 2032-2037.

[12] E. Ugel, G. Giuliano, M. Modesti, Poly (ethylene-co-vinyl acetate)/clay nanocomposites: effect of clay nature and compatibilising agents on morphological, thermal and mechanical properties, Soft Nanosci. Lett. 1 (2011) 105-119.

[13] R. Sonnier, A. Viretto, L. Dumazert, M. Longery, S. Buonomo, B. Gallard, C. Longuer, F. Cavodeau, R. Lamy, A. Freitag, Fire retardant benefits of combining aluminum hydroxide and silica in ethylene-vinyl acetate copolymer (EVA), Polym. Degrad. Stab. 128 (2016) 228-236.

[14] M. Fu, B. Qu, Synergistic flame retardant mechanism of fumed silica in ethylene-vinyl acetate/magnesium hydroxide blends, Polym. Degrad. Stab. 85 (2004) 633-639.

[15] K. Karakus, A.D. Cavdar, F. Mengelog, Effect of boric acid and borax on mechanical, fire and thermal properties of wood flour filled high density polyethylene composites, Measurment 60 (2015) 6-12.

[16] T. Olcese, C. Pagella, Vitreous fillers in intumescent coatings, Prog. Org. Coatings 36 (4) (1999) 231-241.

[17] C. Lu, L. Liu, N. Chen, X. Wang, D. Yang, X. Huang, D. Yao, Influence of clay dispersion on flame retardancy of ABS/PA6/APP blends, Polym. Degrad. Stab. 114 (2015) 16-29.

[18] B. Touré, J.-M. Lopez-Cuesta, M. Longerey, A. Crespy, Incorporation of natura flame retardant fillers in an ethylene-propylene copolymer, in combination with a halogen-antimony system, Polym. Degrad. Stab. 54 (1996) 345-352.

[19] C. Kaynak, N.A. Isitman, Synergistic fire retardancy of colemanite, a natura hydrated calcium borate, in high-impact polystyrene containing brominated epoxy and antimony oxide, Polym. Degrad. Stab. 96 (5) (2011) 798-807.

[20] S. Sener, G. Ozbayoglu, Separation of ulexite from colemanite by calcination, Mineral. Ing. 8 (6) (1995) 697-704.

[21] Ö. Yildiz, The effect of heat treatment on colemanite processing: a ceramics application, Powder Technol. 142 (1) (2004) 7-12

[22] I. Waclawska, L. Stoch, Thermal decomposition of colemanite, Thermochim Acta 126 (1988) 307-318.

[23] R.E. Lyon, R.N. Walters, Pyrolysis combustion flow calorimetry, J. Anal. Appl. Pyrol. 71 (1) (2004) 27-46.

[24] F. Cavodeau, B. Otazaghine, R. Sonnier, J.-M. Lopez-Cuesta, C. Delaite, Fire retardancy of ethylene-vinyl acetate composites - Evaluation of synergistic effects between ATH and diatomite fillers, Polym. Degrad. Stab. 129 (2016) 246-259.

[25] B. Schartel, T.R. Hull, Development of fire-retardet materials - Interpretation of cone calorimeter data, Fire Mater. 31 (5) (2007) 327-354. 